Research article

\title{
Study on eco-efficiency of industrial parks in China based on data envelopment analysis
}

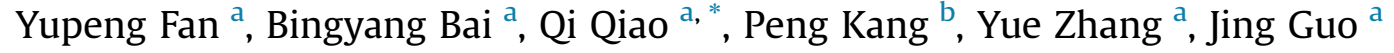 \\ ${ }^{a}$ Key Laboratory of Eco-Industry of the Ministry of Environmental Protection, Chinese Research Academy of Environmental Sciences, Beijing, 100012, China \\ ${ }^{\mathrm{b}}$ State Key Laboratory of Urban and Regional Ecology, Research Center for Eco-Environmental Sciences, Chinese Academy of Sciences, Beijing, 100085, China
}

\section{A R T I C L E I N F O}

\section{Article history:}

Received 3 September 2016

Received in revised form

28 December 2016

Accepted 21 January 2017

Available online 31 January 2017

\section{Keywords:}

Eco-efficiency

Data envelopment analysis

China

Industrial parks

Policy making

Eco-industrial development

\begin{abstract}
A B S T R A C T
China's industrial parks have been playing a crucial role on driving regional economy development, but also been posing threats to local environment due to intensive resource consumption and waste emission. Chinese government facilitated eco-industrial development of industrial park, aiming to output more with less environmental burden. In our study, the eco-efficiency levels of 40 Chinese industrial parks in 2012 were assessed and ranked by Data Envelopment Analysis (DEA). This paper applied indicators relevant to resource, economy, and environment from industrial parks which can well reflect the characteristics of eco-efficiency conforming to the concept of sustainability. This paper introduced how to adjust less sustainable parks to be more sustainable according to the DEA results. The roles of industrial added value per capita, industrial structure, environmental policy and development scale as influence factors of eco-efficiency were discussed. The results show that large differences exist in the eco-efficiency of different industrial parks. It is shown that $20 \%$ of the parks are relatively efficient. $47 \%$ of the study parks being inefficient in terms of scale efficiency show decreasing returns to scale. Policy implementations for the management of industrial parks were also discussed based on the results.
\end{abstract}

๑) 2017 Elsevier Ltd. All rights reserved.

\section{Introduction}

Among different human activities promoting economy growth in China, industrial parks are the major contributor. In the past 30 more years, China established more than 2000 industrial parks, which accounted for more than $60 \%$ of gross national industrial output value and more than 50\% of GDP (Bao, 2013). In 2014, the GDP growth rate of industrial parks, $29.1 \%$, prominently exceeded that of the national average, 7.4\% (CADZ, 2014). However in the meantime they were extensive consumers of energy and resources and huge emitters of pollutants. It was increasingly important to keep productions sustainable over the long run. Eco-efficiency, a popular important indicator, is in conformity with the principle of sustainability (Hicks and Dietmar, 2007). Industrial parks should be optimized to gain high eco-efficiency in order to ensure environmental improvements along with economic growth.

Eco-efficiency is a tool for sustainability analysis, signifying how efficient the economic activity is in consideration of ecosystem's resources and services, and environmental impact. Eco-efficiency

\footnotetext{
* Corresponding author.

E-mail addresses: qiaoqi@craes.org.cn, fanyp@craes.org.cn (Q. Qiao).
}

was primarily stated and used by the World Business Council for Sustainable Development (WBCSD) in 1991. WBCSD provides one of the highly widespread descriptions, namely that eco-efficiency is "achieved by the delivery of competitively priced goods and services that satisfy human needs and enhance quality of life, while progressively reducing ecological impacts and resource intensity throughout the life-cycle to a level at least in line with the Earth's estimated carrying capacity" (WBCSD, 1992). In one words, Ecoefficiency is basically a ratio of economic value to environmental impact, which is able to combine performance of economy and environment.

Recently the eco-efficiency concept has been reinforced by establishing a guideline for evaluating eco-efficiency (ISO 14045, 2012). Eco-efficiency could be evaluated through indexes based on the ratio of economy to environment (ISO 14045, 2012). In this case, eco-efficiency assessment requires environmental performance evaluated by life cycle analysis (LCA) to be connected with the economic value, based on a target and boundary determination. The latest studies show that eco-efficiency is earning more and more preference in various fields. The eco-efficiency concept has been applied at diverse levels of production (Park et al., 2007), service (I. Ribarova et al., 2014), company (Korhonen and Luptacik, 
2004) or one industry (Oggioni et al., 2011; Gössling et al., 2005). Kharel and Charmondusit (2008) quantitatively analyzed ecoefficiency of iron rod industry during the period of 2001-2005 by calculating the eco-efficiency of energy, material consumption, water use, waste generation, and $\mathrm{CO}_{2}$ emission, respectively. Hua et al. (2007) evaluated the eco-efficiency of 32 paper mills along the Huai River. In addition, there are other alternative measures proposed to appraise the eco-efficiency (Glauser and Muller, 1997; Metti, 1999; Schaltegger and Burritt, 2000). The studies mentioned above adopt simple indexes like rates of "economic output per unit of waste" that are close to eco-efficiency from a really restricted viewpoint (Kuosmanen and Kortelainen, 2005). Most eco-efficiency indicators are concentrated on the enterprises or products levels. Decision makers are also interested in employing eco-efficiency principles since they are regarded to lead to national long-term preferences in international competitiveness, especially in the Asian region (Hur et al., 2004; Seppälä et al., 2005). For industrial park, LCA, material flow analysis (MFA), and economic returns are well-known assessment methods (Dong et al., 2013; Yu et al., 2006; Geng et al., 2012), Although they are useful, their indicators may not suitable for eco-efficiency assessment because they were not initially designed for eco-efficiency. Moreover most related studies are performed on cases, and comprehensive evaluations of multiple samples remain very rare. To date, there are some studies on industrial park efficiency (Kicherer et al., 2007; Huppes and Ishikawa, 2005). Most of these studies focus on the productivity efficiency rather than the eco-efficiency (Hu et al., 2010; Ma and Goo, 2005). Some researches have been performed to evaluate the ecoefficiency of industrial parks (Khodakarami et al., 2014; Liu et al., 2015). But their number of samples and the selected indicators is relatively small, which cannot comprehensively reflect the ecoefficiency. Also these researches cannot reveal the current situation due to the earlier study period. Because eco-efficiency has changed since eco-industrial development has been conducted popularly in recent years in China, we need to evaluate the latest eco-efficiency in industrial parks around the country.

Chiu et al. (2009) proposed that eco-efficiency is one of the important problems for the sustainable development of industrial park. In this study, three aspects containing resource, environment and economy of an industrial park were considered to evaluate the eco-efficiency, representing the sustainability of the park.

DEA has been widely employed to estimate the relative efficiency of a set of units since 1978 (Charnes et al., 1978). In this paper DEA was adopted as an approach to assess the relative ecoefficiency of typical industrial parks in China. Calculating and sorting eco-efficiency can help industrial parks in China to facilitate comparisons among different industrial parks and to regulate and adopt appropriate eco-efficiency improvement targets. The final aim of our study is to examine activities with evaluation to improve the sustainability of industry parks.

\section{Method}

\subsection{DEA concept and operation}

Data envelopment analysis is a very effective method to evaluate the relative efficiency of decision-making units (DMUs). DEA examines both production (output) and cost (input) data, looks for the points with the lowest input for maximal output utilizing the chosen parameters, and connects those points to form the efficiency frontier. The units not on the frontier are considered inefficient. A coefficient is granted to each unit, stating its relative efficiency. DEA is becoming an increasingly popular management tool since it has the following advantages in practice: (1) This method is suitable for the synthetic evaluation of the effectiveness of multiple input - multiple output; (2) DEA method does not need to carry out non-dimensional treatment on the data; (3) DEA does not need decision makers to provide the information on weights. The weights can be gained through a programming, that is, no preestimated parameters are needed; (4) The exact functional relationship (function formula) between inputs and outputs need not be considered in DEA.

\subsubsection{Eco-efficiency evaluation with CCR and BCC models}

To evaluate the efficiency of a number of producers, a typical statistical approach is characterized as a central tendency approach and it evaluates producers with respect to an average producer. In contrast, DEA is an extreme point method and compares each producer with only the "best" producers. By the way, in the DEA literature, a producer usually refers to a decision making unit (DMU). DEA is a linear programming based approach for assessing the relative performance of a series of units where the attendance of multiple inputs and outputs makes comparison difficult.

In general, the CCR model invented by Charnes et al. (1978) and the BCC model extended by Banker et al. (1984) based on the CCR model, which have the advantages of multifunctional, reasonable structure, easy operation and convenient for using, are used to measure efficiency. CCR model (Eq. (1)) and BCC model (Eq. (2)) are adopted in this study.

$\min \theta_{c}$

Subject to

$\theta_{c} x_{0}-X \lambda-s^{-}=0$

$Y \lambda-s^{+}=y_{0}$

$\lambda \geq 0, s^{-} \geq 0, s^{+} \geq 0$.

$\theta_{c}$-the input-output efficiency of $\mathrm{DMU}_{0}$ in CCR model;

$X$-the input matrix

Y-the output matrix;

$\lambda$-a 40-dimensional weight vector;

$x_{0}$-the input vector of $\mathrm{DMU}_{0}$

$y_{0}$-the output vector of $\mathrm{DMU}_{0}$;

$s^{-}$- input slack variable vector,

$s^{+}$-output slack variable vector.

$\theta_{c} \leq 1$, and $\theta_{c}$ attains 1 only when both slack vectors are zero and none of the input variables of $\mathrm{DMU}_{0}$ are larger than any linear combination of other DMUs (Cooper et al., 2000).

$\min \theta_{B}$

Subject to

$\theta_{B} x_{0}-X \lambda-s^{-}=0$

$Y \lambda-s^{+}=y_{0}$

$e \lambda=1$

$\lambda \geq 0, s^{-} \geq 0, s^{+} \geq 0$.

e-a 40-dimensional unit vector

$\theta_{B}$-the efficiency of $\mathrm{DMU}_{0}$ in $\mathrm{BCC}$ model, also $\theta_{B} \leq 1$.

Other symbols have the same meanings as in Eq. (1) (Banker et al., 1984).

The CCR model is based on the assumption of constant returns to scale (CRS), while the BCC model is based on the postulation of variable returns to scale (VRS). The efficiency derived from CCR is called overall efficiency (OE), meaning the development level of eco-efficiency in current and future scale. The efficiency under BCC 
is termed pure technical efficiency (PTE), indicating the current eco-efficiency level. Scale efficiency (SE) is the ratio of OE to PTE, which represents the trend of eco-efficiency with the increase of development scale.

Input and output indicators that can reflect the eco-efficiency reasonably are selected from the basic economic and environmental indicators and resource data according to the characteristics and connotation of eco-efficiency (see Table 1). The operability and availability principles are also taken into account in indicator determination.

Among the outputs, four indicators are undesirable: wastewater $\left(\mathrm{Y}_{4}\right)$, solid waste $\left(\mathrm{Y}_{5}\right), \mathrm{COD}\left(\mathrm{Y}_{6}\right)$ and $\mathrm{SO}_{2}\left(\mathrm{Y}_{7}\right)$. Therefore $y_{4}=1 / Y_{4}$, $y_{5}=1 / Y_{5}, y_{6}=1 / Y_{6}, y_{7}=1 / Y_{7}$ are used as output data in this model (Färe et al., 1989).

\subsubsection{Checking change in efficiency}

Performance of industrial parks upon a period of time could be analyzed by the Malmquist Productivity Index (MPI) method grounded on the DEA models (Fuentes et al., 2001). MPI shows the change of the eco-efficiency of the industrial parks during the study time. In our study, MPI is fixed as follows (Thanassoulis, 2001):

$\mathrm{MPI}_{\mathrm{i}}=\left[\frac{D_{t}\left(i_{t+1}\right)}{D_{t}\left(i_{t}\right)} \times \frac{D_{t+1}\left(i_{t+1}\right)}{D_{t+1}\left(i_{t}\right)}\right]^{1 / 2}$

Where $\mathrm{MPI}_{\mathrm{i}}$ represents the Malmquist Productivity Index of DMU i (the industrial park i), $D_{t}\left(i_{t}\right) / D_{t+1}\left(i_{t+1}\right)$ means the efficiency of DMU $\mathrm{i}$ in period $\mathrm{t} / \mathrm{t}+1 ; D_{t}\left(i_{t+1}\right)$ expresses the efficiency of DMU $\mathrm{i}$ in $t$ dataset while utilizing the $t+1$ data of DMU i in place of $t$, and $D_{t+1}\left(i_{t}\right)$ shows the efficiency score of DMU $i$ in $t+1$ dataset while adopting the $t$ data of DMU i replacing $t+1$.

In this paper, $t$ refers to year 2011, and $t+1$ represents year 2012. MPI could be got from the DEA models through weighing change of efficiency. Because MPI is more reliable (Grifell-Tatjé and Lovell, 1999; Tone, 2004) in the circumstance of constant returns to scale (CRS), MPI calculated from CCR model is used to assess the change of eco-efficiency of industrial parks in our study. If $\mathrm{MPI}_{\mathrm{i}}$ is bigger than 1, then park $i$ has an improvement in the efficiency of transforming inputs to outputs from 2011 to 2012 (Zhou et al., 2008; Färe et al., 2011).

\subsection{Industrial parks for study}

Ministry of Environmental protection of China carried out investigations on industrial parks in 2013. Our team is also involved in the work. Forty main national level industrial parks were chosen to make sure that the studied parks reflected the situation of Chinese industrial parks extensively and impartially and that the data could be collected. Actually, all of these industrial parks (shown in Nomenclature) are national demonstration eco-industrial parks

Table 1

Input and output indicators in the DEA model.

\begin{tabular}{|c|c|c|}
\hline Category & Indicators & Description \\
\hline \multirow[t]{3}{*}{ Inputs } & Land $\left(\mathrm{x}_{1}\right)$ & Industrial land area \\
\hline & Energy $\left(\mathrm{x}_{2}\right)$ & $\begin{array}{l}\text { Comprehensive energy } \\
\text { consumption }\end{array}$ \\
\hline & Water $\left(\mathrm{x}_{3}\right)$ & Fresh water consumption \\
\hline Desirable outputs & $\begin{array}{l}\text { Industrial value added } \\
\left(\mathrm{y}_{1}\right)\end{array}$ & Industrial value added \\
\hline \multirow{4}{*}{$\begin{array}{l}\text { Undesirable } \\
\text { outputs }\end{array}$} & Wastewater $\left(\mathrm{y}_{4}\right)$ & Wastewater discharge \\
\hline & Solid waste $\left(\mathrm{y}_{5}\right)$ & Solid waste emissions \\
\hline & $\operatorname{coD}\left(\mathrm{y}_{6}\right)$ & $\begin{array}{l}\text { Chemical oxygen demand } \\
\text { emissions }\end{array}$ \\
\hline & $\mathrm{SO}_{2}\left(\mathrm{y}_{7}\right)$ & $\mathrm{SO}_{2}$ emissions \\
\hline
\end{tabular}

Table 2

Computed results for industrial parks studied.

\begin{tabular}{|c|c|c|c|c|c|}
\hline \multirow[t]{2}{*}{ Industrial park } & \multicolumn{3}{|c|}{ Efficiency } & \multirow[t]{2}{*}{ Returns to scale } & \multirow[t]{2}{*}{ MPI } \\
\hline & $\mathrm{TE}$ & PTE & SE & & \\
\hline DLETD & 0.400 & 1.000 & 0.400 & drs & 1.006 \\
\hline SZHID & 0.275 & 0.286 & 0.960 & drs & 1.055 \\
\hline SZIP & 0.367 & 1.000 & 0.367 & drs & 0.969 \\
\hline YTETD & 0.437 & 0.956 & 0.457 & drs & 1.040 \\
\hline FZETD & 0.572 & 0.657 & 0.870 & irs & 1.285 \\
\hline KSETD & 0.487 & 1.000 & 0.487 & drs & 1.135 \\
\hline WND & 0.374 & 0.678 & 0.551 & drs & 0.981 \\
\hline RZETD & 0.274 & 0.327 & 0.840 & irs & 0.841 \\
\hline QDHIP & 0.443 & 0.595 & 0.746 & irs & 1.008 \\
\hline YZETD & 0.541 & 0.582 & 0.929 & drs & 1.001 \\
\hline KMHID & 0.895 & 1.000 & 0.895 & drs & 0.893 \\
\hline XSETD & 0.241 & 0.319 & 0.756 & irs & 1.145 \\
\hline SHZJHP & 0.340 & 0.389 & 0.875 & irs & 1.020 \\
\hline NCHID & 1.000 & 1.000 & 1.000 & - & 1.068 \\
\hline NBETD & 0.231 & 0.248 & 0.934 & drs & 1.073 \\
\hline WZETD & 0.207 & 0.290 & 0.713 & irs & 1.098 \\
\hline SCHTD & 1.000 & 1.000 & 1.000 & - & 1.000 \\
\hline ZLETD & 0.930 & 0.969 & 0.959 & irs & 0.973 \\
\hline CQYCIP & 0.063 & 0.304 & 0.206 & irs & 0.462 \\
\hline MHETD & 1.000 & 1.000 & 1.000 & - & 1.000 \\
\hline ZZETD & 1.000 & 1.000 & 1.000 & - & 1.000 \\
\hline HFETD & 1.000 & 1.000 & 1.000 & - & 1.000 \\
\hline DYETD & 0.250 & 0.251 & 0.997 & irs & 1.569 \\
\hline NTETD & 0.472 & 0.488 & 0.966 & drs & 1.569 \\
\hline NBHID & 1.000 & 1.000 & 1.000 & - & 1.224 \\
\hline TYETD & 0.685 & 0.809 & 0.847 & irs & 2.230 \\
\hline NCETD & 0.221 & 0.289 & 0.766 & irs & 0.913 \\
\hline CSETD & 1.000 & 1.000 & 1.000 & - & 1.000 \\
\hline LYETD & 0.300 & 0.344 & 0.873 & irs & 1.135 \\
\hline HZETD & 0.283 & 0.295 & 0.959 & drs & 0.345 \\
\hline NJHID & 0.982 & 1.000 & 0.982 & irs & 1.015 \\
\hline XZETD & 0.462 & 0.466 & 0.990 & drs & 1.165 \\
\hline SCSETD & 0.316 & 0.503 & 0.628 & drs & 0.985 \\
\hline WJHID & 0.410 & 0.471 & 0.871 & irs & 1.096 \\
\hline SYETD & 0.565 & 1.000 & 0.565 & drs & 1.261 \\
\hline HAETD & 0.533 & 0.623 & 0.855 & irs & 2.025 \\
\hline WJETD & 1.000 & 1.000 & 1.000 & - & 1.000 \\
\hline YCETD & 0.532 & 0.578 & 0.921 & irs & 0.608 \\
\hline LYGETD & 0.371 & 0.375 & 0.989 & drs & 1.937 \\
\hline GZETD & 0.185 & 0.229 & 0.808 & irs & 0.201 \\
\hline
\end{tabular}

(NDEIPs) or have been approved as potential NDEIPs under construction. Some data for the DEA were extracted from the local statistical yearbooks, documents, environmental reports and local government reports.

\section{Results}

\subsection{Computed results}

\subsubsection{PTE, OE, and SE}

The evaluation results of 40 Chinese industrial parks under the CCR and BCC model are listed in Table 2. In "returns to scale", "drs" means decrease and "ins" means increase. Table 2 shows that the biggest overall efficiency is 1.000 , the smallest being 0.063 and the average value being 0.541 . Amid the 40 industrial parks, 8 parks (NCHID, SCHTD, MHETD, ZZETD, HFETD, NBHID, CSETD, and WJETD) have an overall efficiency of 1.000 . It means that $20 \%$ of the DMUs are efficient while $80 \%$ of the parks are not efficient. Only a small part of parks present efficient in accordance with overall efficiency. These 8 parks are more efficient in converting natural and social resources into economic output and environmental benefits under the present and future scale than the other 32 parks. Therefore, these parks have better eco-efficiency. Industrial structure, technology and management level, geographical position, policies and other conditions in these 8 provinces work well to 
improve resource efficiency and environmental benefits effectively, while promoting the economic development.

There are 16 parks presenting medium eco-efficiency level $(<1.000$, while $\geq 0.400)$ and 16 parks presenting low efficiency $(<0.400)$ according to CCR score. CQYCIP, GZETD, WZETD, NCETD, NBETD, XSETD and DYETD were the top seven worst parks in OE and the average value is 0.200 .

Under BCC model, DLETD, SZIP, KSETD, KMHID, NJHID, and SYETD are also considered efficient in terms of PTE besides the previous 8 efficient parks. The current various conditions function well in their human-nature systems, however as the scale expand, the eco-efficiency will decrease since their SEs signify a decline. According to SE, $47 \%$ of the inefficient parks show descending returns to scale, which implies that eco-efficiency decrease as scale increases for about half of the studied industrial parks. In the process of data envelopment analysis, scale efficiency only refers to the efficiency relevant to scale, technological factors are not taken into account. To some extent, organization and management capacity in these parks can't keep up with the demand of scale extension. Chongqing Yongchuan Gangqiao industrial park ranks last in SE, which means its ecoefficiency will decrease mostly with the expansion of industrial land, population and economic gain.

\subsubsection{Malmquist Productivity Index results}

Table 2 shows that 23 industrial parks have an MPI bigger than 1 , indicating a growth of eco-efficiency from 2011 to 2012. It is clear that Taiyuan economic and technological development zone has the largest MPI being 2.230. From 2011 to 2012 TYETD's industrial added value increased $162 \%$. Annual energy consumption, water consumption, and waste emission per unit value added were all largely reduced. With the deepening of the integration of coal resources, Shanxi (Province of TYETD) steps into the era of big mines, the market demand of coal machine equipment is growing fast. TYETD has introduced 8 leading enterprises including Sany heavy equipment, China coal technology and engineering group, Australia valley longwall, and other high-end coal machine enterprises from 2011 to 2012. Since then, TYETD actively took measures of industrial green transformation and technology innovation to promote the industrial Upgrading. There are 6 industrial parks keeping the same eco-efficiency compared to other parks from 2011 to 2012 since the MPI is 1 . The last 11 industrial parks have an MPI smaller than 1, meaning these parks have a decrease in eco-efficiency. Ganzhou economic and technological development zone has the smallest MPI at 0.201 . Its energy consumption, water consumption, and waste emission make a big increase from 2011 to 2012, especially the water consumption.

\subsection{Adjustment based on results}

DEA lets a DMU to recognize the extent to which it ought to coordinate the inputs and outputs to accomplish an efficient level of transforming input to output. There are two methods for identifying this level: projecting and benchmarking (Stokes et al., 2007). Because the target was to provide actual advices for industrial parks' management practices embodying 'eco-industrial development', the BCC model was applied as a result of its concentration on the current efficiency of policies and management approaches. Fuzhou economic and technological development zone supplies a sample presenting how to regulate the park based on the results. It has a BCC efficiency of 0.657 , showing that this park should reduce the energy, water consumption and land use by $34.3 \%$ in order to be DEA efficient. Nevertheless, as shown in the slacks dataset, a requisite procedure for full DEA efficiency is as follows. $\mathrm{SO}_{2}$ should be reduced by about 99.9\%. The reference DMUs of FZETD are MHETD, WJETD, and HFETD. Compared with these parks, FZETD has much to do to reduce resource consumption and control pollution. Considering FZETD's situation, promoting high-tech industries and developing tertiary industry may be a wise choice, for FZETD is located in the downstream of Minjiang estuary to the sea, enjoying a favorable geographical position (convenient transportation and more chances to trade). Take GZETD as another

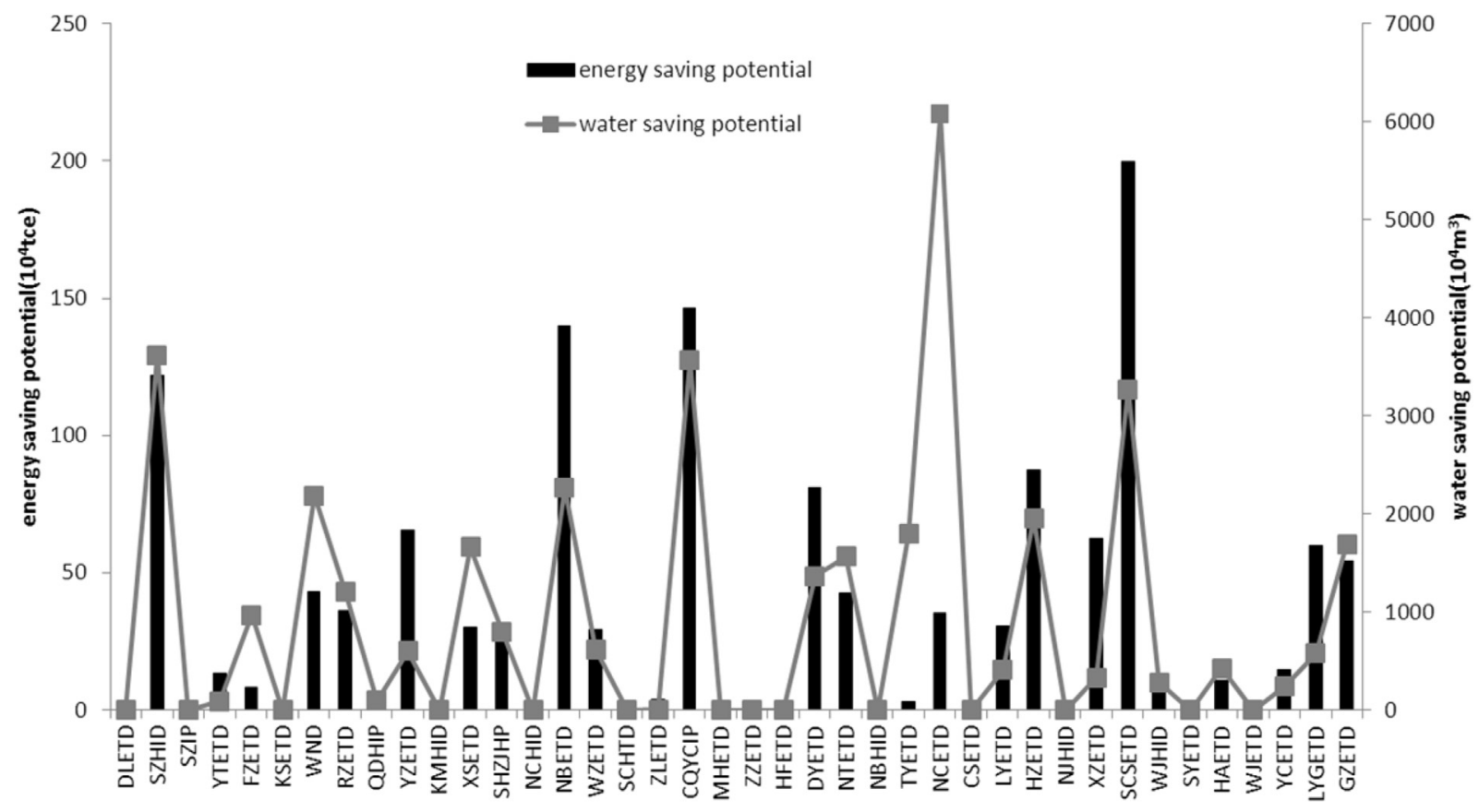

Fig. 1. Energy and water saving Potential in the industrial parks in China. 


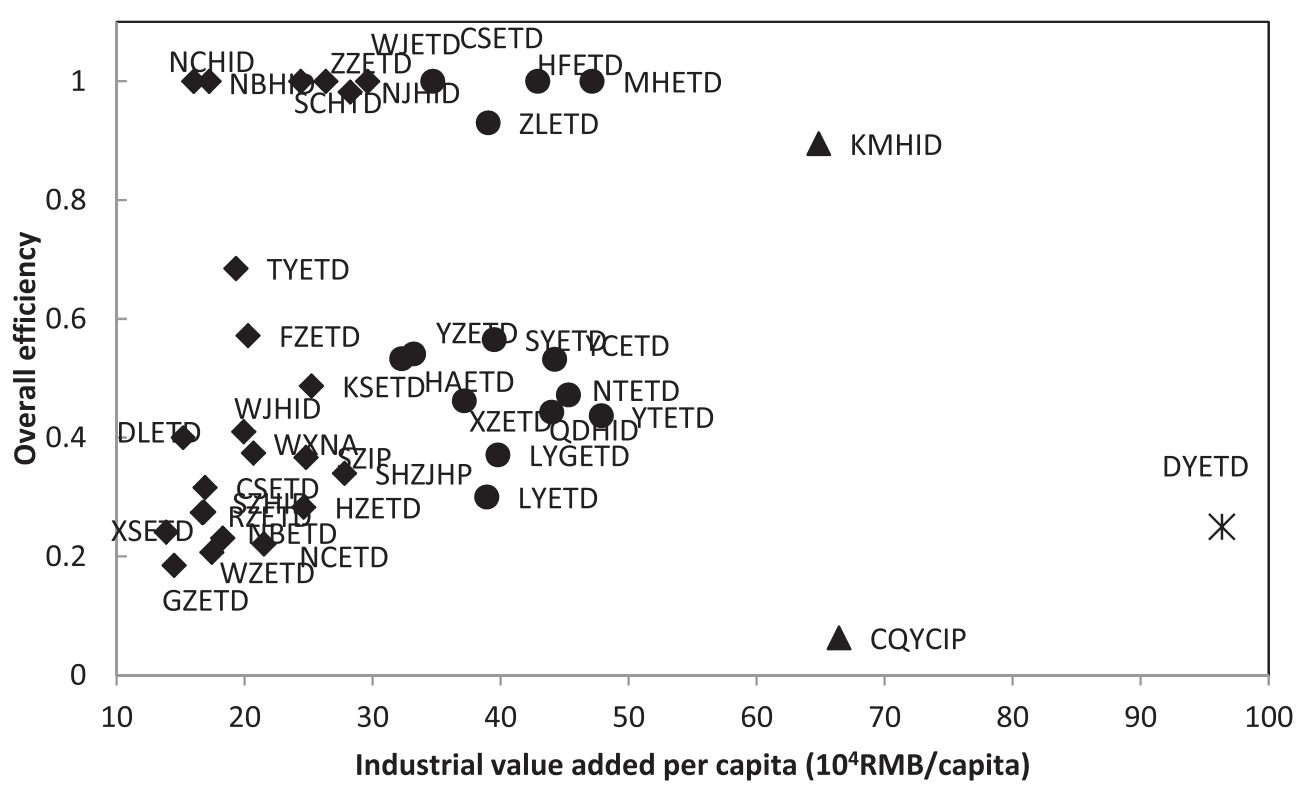

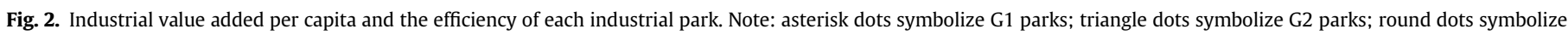
parks in G3; rhombus dots symbolize parks in G4.

example to show how to achieve complete efficient. GZETD ranks the last in terms of BCC efficiency being 0.229 . The consumption of energy, water and land use should be controlled within $22.9 \%$ of the original value compared with the frontier constructed of the reference DMUs. In addition, $\mathrm{SO}_{2}$ needs to be reduced by $99.9 \%$. From the whole point of view, $\mathrm{SO}_{2}$ is the limiting factor for ecoindustrial development. In terms of benchmarking, the kernel step is selecting one or more benchmarks for every inefficient park. Usually, one can first browse the reference parks and pick the most suitable ones in consideration of natural and social conditions. For example, KSETD could be benchmark for WND. KSETD is one of WND's reference DMUs based on DEA results. Furthermore, they are both located in Yangtze River Delta region and have similar conditions.

DEA can investigate the conserving potential of energy and water in industrial parks in China in this study. Fig. 1 shows the total potential of energy and water conservation in the industrial parks studied. According to Fig. 1, the energy saving potential of four parks surpasses 1 million tce (tonnes of coal equivalent) in 2012. Suzhou Changshu economic and technological development zone has the greatest energy saving potential, followed by CQYCIP, NBETD and SZHID, in decreasing order. TYETD has the lowest potential of energy saving in inefficient parks. CQYCIP has the lowest overall efficiency (0.063), it however does not have the largest potential of energy saving. Although the overall efficiency of SCSETD is 0.316 , it has a bigger energy saving potential than that of CQYCIP. The reason is that SCSETD has a much larger amount of energy consumption $(2,372,685$ tce) than that of CQYCIP $(1,545,864$ tce). As shown in Fig. 1, there are six provinces which have a potential of water saving more than 20 million $\mathrm{m}^{3}$. The largest water saving potential is in NCETD being 60.84 million $\mathrm{m}^{3}$, and SZHID, CQYCIP, SCSETD, NBETD and WND follow in descending order. The water saving potential of ZLETD is the lowest in DEA inefficient parks. The water saving potential of CQYCIP is not the largest in spite of its lowest efficiency. The water consumption of SZHID and NCETD is much larger than that of CQYCIP. Although these three industrial parks are located in water abundance areas, they should create opportunities to promote wastewater reuse to save water.

\subsection{Influence factor}

\subsubsection{Industrial value added per capita}

Economic value influences eco-efficiency in two manners: first, an increase in industrial value added per capita signifies a growth in economic scale and unavoidably brings about an increase in resource consumption and more environmental emissions. Second, an increase in industrial value added per capita can promote more research and develop investment in enterprises (Kor, 2006; Manyika, 2012), and advanced technology and management could improve the resource efficiency and pollution control ability, resulting in higher eco-efficiency. CQYCID and DYETD verified the first impact mechanism. It is clearly shown in Fig. 2 that ecoefficiency were positively correlated with economic development of the parks in the range of $0.0<\mathrm{TE}<0.8$ (excluding KMHID, CQYCID, and DYETD). The high economic profit could also lead to forming good concept of sustainable development which has a positive impact on eco-efficiency.

According to SPSS's (Statistical Package for Social Science) Kmeans cluster analysis, the parks were divided into 4 groups (Fig. 2): (G1) DYETD as high industrial value added per capital parks; (G2) KMHID, CQYCIP as medium-high industrial value added per capital parks; (G3) MHETD, YTETD etc. as middle industrial value added per capital parks; (G4) FZETD, GZETD etc. as low industrial value added per capital parks. This distribution also indicates the above influencing mechanism: one part of parks goes up and one part of parks goes down in eco-efficiency by influence of economic value increase.

\subsubsection{Industrial structure}

Industrial structure has a significant impact on the ecoefficiency of industrial parks in China. To explore the correlation between industrial structure and eco-efficiency, we divide the 40 industrial parks into three groups (Table 3 ) in terms of the ratio of heavy industry/light industry and main industries of each park in 2012: light industry, heavy industry, and mixed industry parks. Given the situations of sample parks, the criteria are as follows: in heavy industry parks, over $60 \%$ of industry value added is occupied by heavy industry. The main industries in these parks are mining, 
Table 3

Classification of industrial parks based on industrial structure.

\begin{tabular}{|c|c|}
\hline Industrial structure & Industrial parks \\
\hline Light industry & YTETD, KSETD, WND, YZETD, KMHID, NCHID, WZETD, SCHTD, ZLETD, MHETD, ZZETD, HFETD, NBHID, CSETD, NJHID, WJHID, WJETD, UCETD \\
\hline Mixed industry & SZHID, SZIP, FZETD, QDHIP, SHZJHP, NBETD, DYETD, NTETD, TYETD, HZETD, SYETD, HATED, LYGETD \\
\hline Heavy industry & DLETD, RZETD, XSETD, CQYCIP, NCETD, LYETD, XZETD, SCSETD, GZETD \\
\hline
\end{tabular}

chemicals, metallurgy, etc. In light industry parks, light industry creates $>40 \%$ of the total industry value added. The main industries are food processing, textiles, household appliances etc. In mixed industry parks, the proportions of heavy industry and light industry are nearly equaled and there are no distinct leading industries.

Light industry parks have a mean efficiency of 0.766 , compared to 0.274 for heavy industry parks and 0.414 for mixed industry parks. Light industry parks have higher eco-efficiency than heavy and mixed industry parks. Because light industry relies on labor more than resources, such parks tend to perform better in our analysis.

On one hand, if energy industry (e.g. heat-power industry) and raw material processing industry (e.g. metal industry) are the main industry in an industrial park, the eco-efficiency will be lagged severely by these intensive energy consumption and high-pollution industries. On the other hand, the proportion of high tech industry plays a positive role in improving the eco-efficiency of industrial park. The pillar industries of GZETD are non-ferrous metals industry, new materials industry, and machinery manufacturing. Non-ferrous metals industry cluster mainly includes tungsten and rare earth processing industry and the relevant mining industry (GZETD, 2014). These are resource dependent industries which have low environmental performance, and the human resource is not the main power for development. Therefore GZETD has a very low eco-efficiency. Shanghai minhang economic and technological development zone has three major industries of mechanical electronic industry (rail transportation equipment, power station equipment), healthcare and medical industry (blood products, common medicines) and light industry (food, beverages, etc.). All these industries have high added value for their final products. Therefore MHETD has a full efficiency. YCETD has both traditional resource dependent industries and high-tech industries, so it has a medium eco-efficiency.

\subsubsection{Local environmental policy and development scale}

Promoting positive environmental policy can reduce environmental pollution, and abate economic and health loss. Also, it can improve resource utilization efficiency, stimulate progress and environmental technology innovation. Environmental policy includes resources taxes, sewage charges, emission trading, subsidies of reducing emissions, environmental standards, etc. These positive measures may cut down the emissions from resource consumption, and promote the growth of eco-efficiency. All the efficient parks have strict environmental administration policies and rigid environmental access mechanism. Through an investigation, Wang et al. (2011) also found that the overall eco-efficiency and the environmental performance had achieved great improvements in Shandong Province's pulp and paper industry via implementing a stricter environmental regulation. HFETD has a rigid environmental access system, and increase environmental infrastructure investment. These will eliminate the excessive resources consumption and pollution emissions from the source, process and the end. Several big producers were not permitted to move into HFETD due to large energy-consuming and environmental emissions. Over 50 coal-burning boilers were phased out due to their low energy efficiency and high emissions (Fan et al., 2017). Consequently HFETD has an eco-efficiency value of 1.000 .

Industrial value added can reflect the scale of economy of the park to a large extent. Fig. 3 shows that overall efficiency is directly proportional to the scale of economy of the inefficient industrial parks. Economies of scale theory in traditional economics advocates that the expansion of enterprise scale leads to various kinds of professional division of labor, so as to improve the production efficiency of enterprises, which is the most primitive understanding of the scale economy. In the modern enterprise theory, economies of scale have more profound understanding. High efficiency usually requires large-scale production to raise huge amounts of money, implementation of meticulous management and supervision of ongoing activities. In large scale enterprises, the clear labor division, complete process, technology and management level and other factors are ahead of small scale enterprises, which lead to higher production efficiency. In addition to the inner enterprises, Industrial park also has external economies of scale. It belongs to spatial agglomeration economy, which refers to that the agglomeration and connection of several factories and enterprises in the unified spatial region could decrease the production cost and pollution emissions (saving resources consumption) and thus increase the economic benefit. SYETD has a big economic scale, hereby it has opportunities to implement much cooperation between enterprises (Geng et al., 2014; Liu et al., 2014). Consequently SYETD has a higher efficiency in the inefficient parks.

\section{Discussion and policy implications}

Large differences exist among 40 parks in overall efficiency. The average efficiency is only 0.541 , the standard deviation is 0.301 , and the dispersion coefficient is 0.556 . According to geography, Chinese regions in the mainland can be separated into 7 areas: Northeast, North China, Central China, East China, South China, Northwest, and Southwest. Fig. 4 displays the difference in efficiency of the study parks among the 7 areas. The East China has the highest average efficiency score. 6 of the 8 efficient parks in the CCR model are located in East China. All the industrial parks studied are constructing the national demonstrate eco-industrial parks, or have been accepted for this title. Most of the parks (33) are concentrated

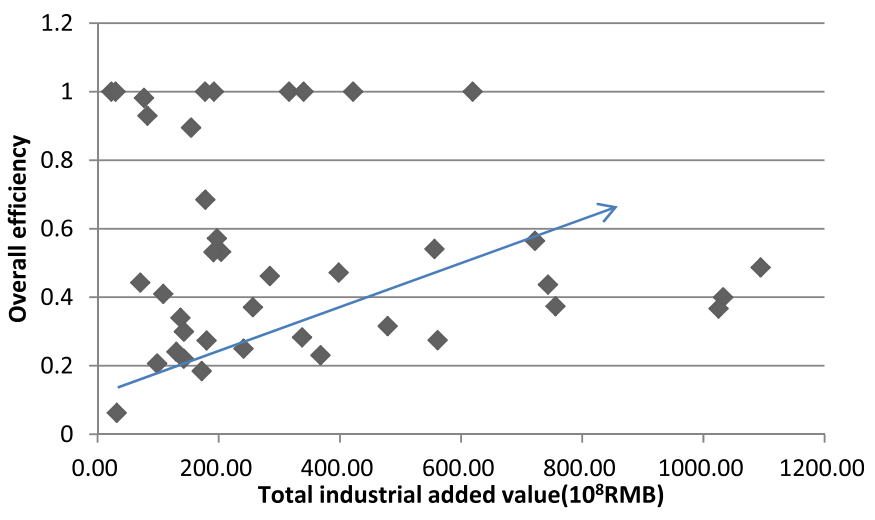

Fig. 3. The relationship between economy scale and overall efficiency. 

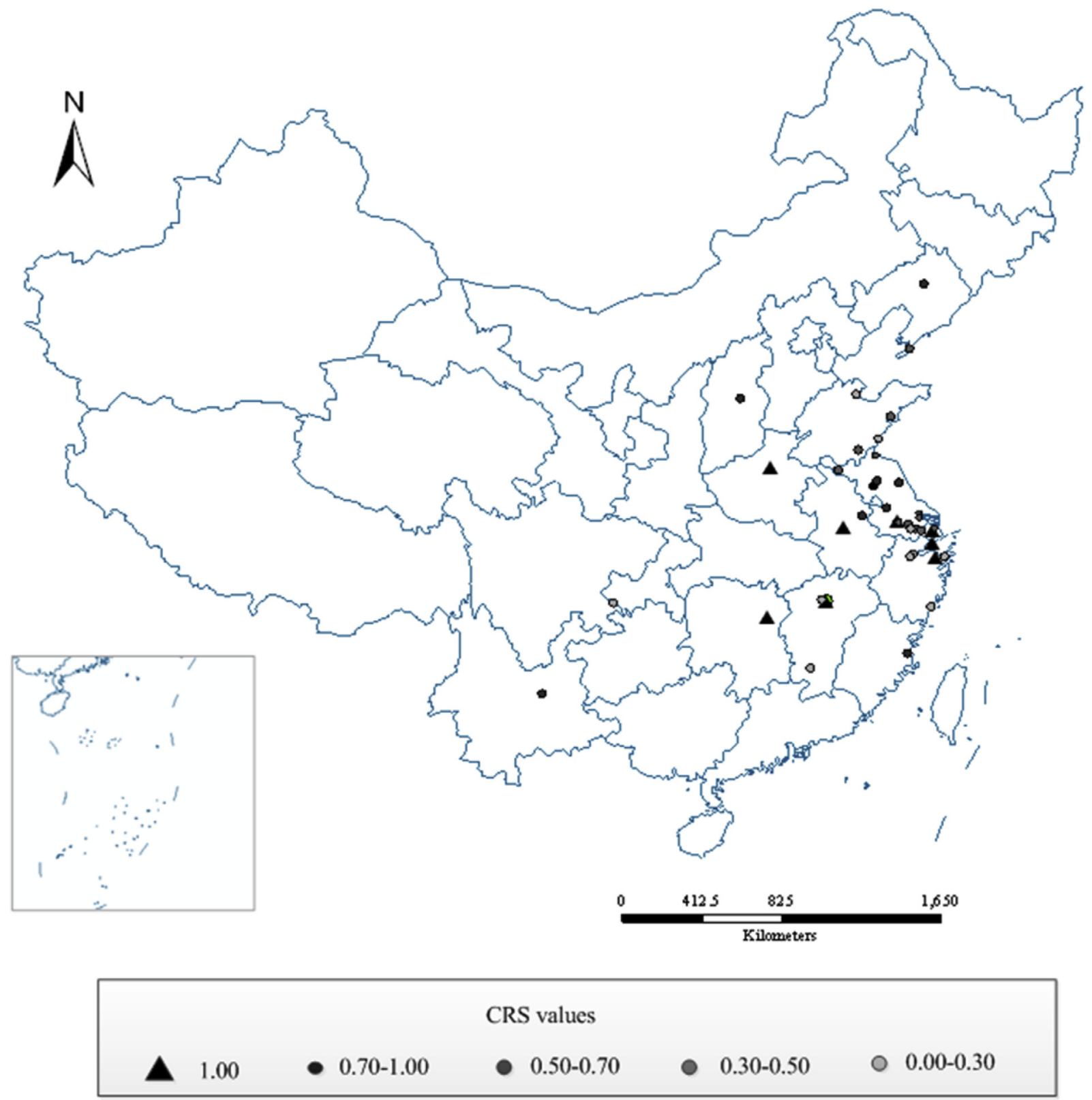

Fig. 4. Regional disparity of DEA efficiencies.

in East China. The distribution of the remaining parks is: 2 parks in Northeast, 2 parks in Central China, 2 parks in Southwest and 1 park in North China. From this viewpoint, the parks located in the developed regions are inclined to conduct eco-industrial development. We should put forward the eco-industrial development from east to west in our country. To promote industrial parks towards sustainable development, an information platform should be set up for national level industrial parks. For one side, the platform can work as a data and information collection system for industrial parks and aid the government to manage parks. For the other side, it can promote the sharing of the successful experiences of efficient parks to raise the overall performance of leftover industrial parks. The inefficient parks should learn and adopt the advanced management and technology from the reference DMUs to reduce their inputs and improve outputs through projecting and benchmarking. The platform can also provide byproduct/waste exchange information to facilitate industrial symbiosis.
With high-speed development, economic output becomes the most important criterion to measure the performance of industrial parks. Industrial efficiency mostly refers to the economic efficiency, while this kind of one-sided viewpoint lets enterprise ignore other factors in the development. Only to pursue economic benefits without considering the environmental and social aspects made "economy first" model be a common phenomenon for several decades in our country. However, in the pursuit of sustainable development, eco-industrial development will be the inevitable trend for the future transformation of industrial parks, and establishment of eco-efficiency concept is imperative. It needs to be aware that the economic benefit is not the only goal that the enterprise pursues. Establishing the concept of eco-efficiency is the first step to change the awareness of the top leadership in the strategic level.

From the level of local government and park administration committee, environmental policy should be made integrating with 
industrial policy. Strict environmental standard could force the firms to take options for further cleaner production and advanced treatment technology. For instance, HFETD serves as a role model for environmental access policy. Rational industrial policy would guide the direction of industry development towards a more sustainable way, and lead to a more sustainable industrial structure. Pillar industries in some industrial parks are coal-based electric power industry and raw materials processing industry mainly including metal smelting and processing industry, which are mostly high energy consumption and high pollution industry. Irrational industrial structure seriously affected source abatement efficiency level. We should enhance the adjustment of industrial structure, extend the industrial chain, transform and upgrade traditional industries, and promote the development of "resource saving and environment friendly" industry. In this regard, TYETD has set a good example. From the whole country, a promotion system about governmental officers should be established with regards of environment. As a general rule, officers' promotion is depended on economic growth rather than social and environmental performance (Liu et al., 2012). This will lead local governments to concentrate on economic growth with less consideration of environment quality. In addition, economic means are effective regulations to promote sustainable development of industrial parks. For example, resource tax can help adjust the industrial activities and obtain money for upholding related research and development activities. Furthermore financial subsidies should be provided to aid those companies in engaging in eco-industrial development in order that they can have enough capital to carry out their innovative measures such as eco-design, cleaner production, process synthesis, and advanced end-of-pipe treatment.

\section{Conclusion}

Industrial parks have been contributing factors for economic growth and environmental pollution. The concept of eco-efficiency is used more and more in public environmental discussion. Generally eco-efficiency has been specified as a common target of producing economic value while abating environmental impact. In this study we evaluate eco-efficiency level of 40 industrial parks in China based on DEA model. Results show that 20\% of the parks (e.g. NCHID, SCHTD) are relatively efficient in OE. DLETD, SZIP, KSETD, KMHID, NJHID, and SYETD are also considered efficient under current development scale. $47 \%$ of the parks being inefficient in SE show decreasing returns to scale. CQYCIP is the lowest efficient park in both CCR and BCC model. Large differences exist among different parks in eco-efficiency. Influence factors of eco-efficiency were analyzed and some implications were proposed accordingly from the park and firm level. Based on the results, the park with low eco-efficiency can be regulated towards a more efficient one. Industrial value added per capita, industrial structure, policy and scale are the most important influencers for eco-efficiency and we need to form effective mechanism of policy making to increase ecoefficiency according to different situations in different parks.

Finally, there are a few restraints in this study. In order to make eco-efficiency become a more useful indicator for sustainable development, it must be integrated with other indicators and tools, such as carrying capacity indicators, social and cultural indicators, and LCA for a time-scale analysis. The indices used in this ecoefficiency evaluation cannot cover all the sustainable issues of industrial parks. Next studies should expand more variables reflecting the eco-efficiency and identify the crucial environmental problems to gain a more significant index system. The static and cross-sectional framework in this paper should also be expanded towards dynamic eco-efficiency analysis over a long run.

\section{Acknowledgements}

This research is financially supported by the National Natural Science Foundation of China (No. 71373248). The authors would like to thank anonymous reviewers for their helpful comments.

\section{Nomenclature}

\begin{tabular}{|c|c|}
\hline Industrial park & Abbreviation \\
\hline Dalian economic and technological development zone & DLETD \\
\hline Suzhou high-tech industry development zone & SZHID \\
\hline Suzhou industrial park & SZIP \\
\hline Yantai economic and technological development zone & YTETD \\
\hline Fuzhou economic and technological development zone & FZETD \\
\hline Kunshan economic and technological development zone & KSETD \\
\hline Wuxi new district & WND \\
\hline Rizhao economic and technological development area & RZETD \\
\hline Qingdao high-tech industrial park & QDHIP \\
\hline Yangzhou economic and technological development zone & YZETD \\
\hline Kunming high-tech industry development zone & KMHID \\
\hline Xiaoshan economic and technological development zone & XSETD \\
\hline Shanghai Zhangjiang high-tech park & SHZJHP \\
\hline Nanchang high-tech industry development zone & NCHID \\
\hline Ningbo economic and technological development zone & NBETD \\
\hline Wenzhou economic and technological development zone & WZETD \\
\hline Shanghai Caohejing high-tech development zone & SCHTD \\
\hline Zhonglou economic development zone, changzhou & ZLETD \\
\hline Chongqing Yongchuan Gangqiao industrial park & CQYCIP \\
\hline $\begin{array}{l}\text { Shanghai Minhang economic and technological development } \\
\text { zone }\end{array}$ & MHETD \\
\hline Zhengzhou economic and technological development zone & ZZETD \\
\hline Hefei economic and technological development zone & HFETD \\
\hline Dongying economic and technological development zone & DYETD \\
\hline Nantong economic and technological development zone & NTETD \\
\hline Ningbo high-tech industry development zone & NBHID \\
\hline Taiyuan economic and technological development zone & TYETD \\
\hline Nanchang economic and technological development zone & NCETD \\
\hline Changsha economic and technological development zone & CSETD \\
\hline Linyi economic and technological development zone & LYETD \\
\hline Hangzhou economic and technological development zone & HZETD \\
\hline Nanjing high-tech industry development zone & NJHID \\
\hline Xuzhou economic and technological development zone & XZETD \\
\hline Changshu economic and technological development zone,Suzhou & SCSETD \\
\hline Wujin high-tech industry development zone & WJHID \\
\hline Shenyang economic and technological development zone & SYETD \\
\hline Huai'an economic and technological development zone & HAETD \\
\hline Wujin economic and development zone & WJETD \\
\hline Yancheng economic and technological development zone & YCETD \\
\hline Lianyungang economic and technological development zone & LYGETD \\
\hline Ganzhou economic and technological development zone & GZETD \\
\hline
\end{tabular}

\section{References}

Banker, R.D., Charnes, A., Cooper, W.W., 1984. Some models for estimating technical and scale efficiencies in data envelopment analysis. Manage. Sci. 30 (9), 1078-1093.

Bao, X., 2013. Exploring a Road to Ecological Transformation for Industrial Parks. Economic Daily. The Economic Daily Press Group, Beijing, China.

CADZ (China Association of Development Zone), 2014. China Development Zone Statistics. China finance and Economics Press, Beijing.

Charnes, A., Cooper, W.W., Rhodes, E., 1978. Measuring the efficiency of decision making units. Eur. J. Oper. Res. 2 (6), 429-444.

Chiu, A.S.F., Ward, V.J., Massard, G., 2009. Introduction to the special issue on advances in life-cycle approaches to business and resource management in the Asia-Pacific region. J. Clean. Prod. 17, 1237-1240.

Cooper, W.W., Seiford, L.M., Kaoru, T., 2000. Data Envelopment Analysis, a Comprehensive Text with Models, Applications, Reference and DEA-solver Software. Kluwer Academic Publisher, Morwell.

Dong, H., Geng, Y., Xi, F., Fujita, T., 2013. Carbon footprint evaluation at industrial park level: a hybrid life cycle assessment approach. Energ. Policy 57, 298-307. 
Fan, Y., Qiao, Q., Fang, L., Yao, Y., 2017. Emergy analysis on industrial symbiosis of an industrial park-A case study of Hefei economic and technological development area. J. Clean. Prod. 141, 791-798.

Färe, R., Grosskopf, S., Lovell, C.A.K., Pasurka, C., 1989. Multilateral productivity comparison when some outputs are undesirable: a nonparametric approach. Rev. Econ. Stat. 71, 90-98.

Färe, R., Grosskopf, S., Margaritis, D., 2011. Malmquist Productivity Indexes and DEA [M]//Handbook on Data Envelopment Analysis. Springer, US, pp. 127-149.

Fuentes, H.J., Grifell-Tatjé, E., Perelman, S., 2001. A parametric distance function approach for Malmquist productivity index estimation. J. Prod. Anal. 15 (2) 79-94.

Geng, Y., Fu, J., Sarkis, J., Xue, B., 2012. Towards a national circular economy indicator system in China: an evaluation and critical analysis. J. Clean. Prod. 23 (1) 216-224.

Geng, Y., Liu, Z., Xue, B., Dong, H., Fujita, T., Chiu, A., 2014. Emergy-based assessment on industrial symbiosis: a case of Shenyang economic and technologica development zone. Environ. Sci. Pollut. R. 21 (23), 13572-13587.

Glauser, M., Müller, P., 1997. Eco-efficiency: a prerequisite for future success. CHIMIA Int. J. Chem. 51 (5), 201-206.

Gössling, S., Peeters, P., Ceron, J.P., Dubois, G., Patterson, T., Richardson, R.B., 2005. The eco-efficiency of tourism. Ecol. Econ. 54 (4), 417-434.

Grifell-Tatjé, E., Lovell, C.A.K., 1999. A generalized Malmquist productivity index. Top 7 (1), 81-101.

GZETD, 2014. Ganzhou Economic and Technological Development Zone.

Hicks, C., Dietmar, R., 2007. Improving cleaner production through the application of environmental management tools in China. J. Clean. Prod. 15 (5), 395-408.

Hu, J.L., Han, T.F., Yeh, F.Y., Lu, C.L., 2010. Efficiency of science and technology industrial parks in China. J. Manag. Res. 10 (3), 151.

Hua, Z., Bian, Y., Liang, L., 2007. Eco-efficiency analysis of paper mills along the Hua River: an extended DEA approach. Omega 35 (5), 578-587.

Huppes, G., Ishikawa, M., 2005. Eco-efficiency and its xsTerminology. J. Ind. Ecol. (4), 43-46.

Hur, T., Kim, I., Yamamoto, R., 2004. Measurement of green productivity and its improvements. J. Clean. Prod. 21, 673-683.

ISO 14045, 2012. Assessment of Product Systems d Principles, Requirements and Guidelines.

Kharel, G.P., Charmondusit, K., 2008. Eco-efficiency evaluation of iron rod industry in Nepal. J. Clean. Prod. 16 (13), 1379-1387.

Khodakarami, M., Shabani, A., Saen, R.F., 2014. A new look at measuring sustainability of industrial parks: a two-stage data envelopment analysis approach. Clean. Technol. Environ. 16 (8), 1577-1596.

Kicherer, A., Schaltegger, S., Tschochohei, H., Pozo, B.F., 2007. Eco-efficiency. Int. J. Life Cycle Ass. 12 (7), 537-543.

Kor, Y.Y., 2006. Direct and interaction effects of top management team and board compositions on R\&D investment strategy. Strategic Manag. J. 27 (11) 1081-1099.

Korhonen, P.J., Luptacik, M., 2004. Eco-efficiency analysis of power plants: an extension of data envelopment analysis. Eur. J. Oper. Res. 154 (2), 437-446.
Kuosmanen, T., Kortelainen, M., 2005. Measuring eco-efficiency of production with data envelopment analysis. J. Ind. Ecol. 9 (4), 59-72.

Liu, Z., Geng, Y., Zhang, P., Dong, H., Liu, Z., 2014. Emergy-based comparative analysis on industrial clusters: economic and technological development zone of Shenyang area, China. Environ. Sci. Pollut. R. 21 (17), 10243-10253.

Liu, L., Zhang, B., Bi, J., 2012. Reforming China's multi-level environmental governance: lessons from the 11th Five-Year Plan. Environ. Sci. Policy 21, 106-111.

Liu, W., Tian, J., Chen, L., Lu, W., Gao, Y., 2015. Environmental performance analysis of eco-industrial parks in China: a data envelopment analysis approach. J. Ind. Ecol. 19 (6), 1070-1081.

Ma, Y.F., Goo, Y.J., 2005. Technical efficiency and productivity change in China's high-and new-technology industry development zones. Asian Bus. Manag. 4 (3), 331-355.

Manyika, J., 2012. Manufacturing the Future: the Next Era of Global Growth and Innovation. McKinsey Global Institute.

Metti, G., 1999. Global Environmental Factors and Eco-efficiency. Beverage World, pp. 2-83.

Oggioni, G., Riccardi, R., Toninelli, R., 2011. Eco-efficiency of the world cement industry: a data envelopment analysis. Energ. Policy 39 (5), 2842-2854.

Park, P.-J., Tahara, K., Inaba, A., 2007. Product quality-based eco-efficiency applied to digital cameras. J. Environ. Manage 83 (2), 158-170.

Ribarova, I., Stanchev, P., Dimova, G., Assimacopoulos, D., 2014. A first iteration of an eco-efficiency assessment of Sofia's urban water system. Procedia Eng. 70, $1411-1420$.

Schaltegger, S., Burritt, R., 2000. Contemporary Environmental Accounting: Issues, Concepts and Practice. Greenleaf Publishing, Sheffield.

Seppälä, J., Melanen, M., Mäenpää, I., Koskela, S., Tenhunen, J., Hiltunen, M.-R., 2005 How can the eco-efficiency of a region be measured and monitored? J. Ind. Ecol. 9, 117-130.

Stokes, J.R., Tozer, P.R., Hyde, J., 2007. Identifying efficient dairy producers using Data Envelopment Analysis. J. Dairy Sci. 90, 2555-2562.

Thanassoulis, E., 2001. Introduction to the Theory and Application of Data Envelopment Analysis: a Foundation Text with Integrated Software. Klumer Academic Publisher, Boston.

Tone, K., 2004. Malmquist Productivity Index[M]//Handbook on Data Envelopment Analysis. Springer, US, pp. 203-227.

Wang, Y., Liu, J., Hansson, L., Zhang, K., Wang, R., 2011. Implementing stricter environmental regulation to enhance eco-efficiency and sustainability: a case study of Shandong Province's pulp and paper industry, China. J. Clean. Prod. 19 (4), 303-310.

WBCSD (World Business Council for Sustainable Development), 1992. Changing course. In: Schmidheiny, Stefan, et al. (Eds.), With the Business Council for Sustainable Development. MIT Press, Cambridge.

Yu, C.G., Lee, I.B., Lee, S.J., Choe, S.G., Jeon, H.D., 2006. Modeling of eco-industrial park (EIP) through material flow analysis (MFA). Korean Chem. Eng. Res. 44 (6), 579-587.

Zhou, P., Ang, B.W., Poh, K.L., 2008. A survey of data envelopment analysis in energy and environmental studies. Eur. J. Oper. Res. 189 (1), 1-18. 